\title{
Modification of a rumen fluid priming technique for measuring in vitro neutral detergent fiber digestibility ${ }^{1}$
}

\author{
J. P. Goeser, P. C. Hoffman, and D. K. Combs ${ }^{2}$ \\ Department of Dairy Science, University of Wisconsin, Madison 53706
}

\section{ABSTRACT}

Recently, we developed an alternate method to measure in vitro neutral detergent fiber (NDF) digestibility (ivNDFD) based on a primed rumen fluid inoculum. Pretreating rumen fluid inoculum with cellulose and holding the inoculum until it generated $0.3 \mathrm{~mL}$ of gas/ $\mathrm{mL}$ of rumen fluid before inoculating forage samples improved ivNDFD assay repeatability but depressed ivNDFD means. Our objective in this study was to determine if pretreating rumen fluid with a mixture of carbohydrates and urea would affect the ivNDFD mean and variance. We also used the modified procedure as a reference assay to calibrate near-infrared reflectance spectroscopy (NIRS) to predict 24-, 30-, and 48-h ivNDFD. Two experiments were completed. In experiment A, 3 ivNDFD assays modified from the method of Goering and Van Soest were evaluated over 24, 28, 48,54 , and $72 \mathrm{~h}$ by using dried, ground alfalfa $(1 \mathrm{~mm})$ or wheat straw $(0.5 \mathrm{~g})$ sealed in Ankom F57 forage fiber bags. Bags were placed individually in 125-mL Erlenmeyer flasks and incubated with Goering and Van Soest media and $10 \mathrm{~mL}$ of rumen fluid. Rumen fluid was collected before feeding from 2 cannulated cows fed a high-forage diet and was prepared in 1 of 3 ways: 1) pooled rumen fluid was strained and used immediately to inoculate flasks (modified Goering and Van Soest method); 2) strained, pooled fluid was combined with buffer, reducing solution, and $1.25 \mathrm{mg}$ of primer $/ \mathrm{mL}$ of rumen fluid and allowed to produce $0.12 \mathrm{~mL}$ of gas/ $\mathrm{mL}$ of rumen fluid before sample inoculation [CombsGoeser (CG) method]; or 3) the CG method was used without the primer mixture (unprimed method). The assay was repeated 5 times, with 5 time points $(24,28$, 48,54 , and $72 \mathrm{~h}$ ) and 2 subsamples per time point for each method. Neutral detergent fiber was analyzed using an Ankom ${ }^{200}$ forage fiber analyzer and ivNDFD was determined as follows: ivNDFD $(\%$ of NDF $)=100 \times$

\footnotetext{
Received September 24, 2008.

Accepted March 6, 2009.

${ }^{1}$ This research was funded by USDA Hatch multistate project NE-

${ }^{2}$ Corresponding author: dkcombs@wisc.edu
} 1024 .
$\left[\left(\mathrm{NDF}_{0 \mathrm{~h}}-\mathrm{NDF}_{\text {residue }}\right) /\left(\mathrm{NDF}_{0 \mathrm{~h}}\right)\right]$. Results were analyzed using a mixed model procedure, and data were blocked by method to obtain repetition sums of squares, which were compared by an $F$-test to assess interassay error. Repetition sums of squares were reduced with the CG method compared with the Goering and Van Soest method (19 vs. 228), and mean ivNDFD estimates were similar at 28, 48, and $54 \mathrm{~h}$. In experiment B, 24-, 30-, and 48-h ivNDFD data for 54 feeds were determined in triplicate using the $\mathrm{CG}$ method, and corresponding samples were then scanned with an NIRS instrument. Calibrations were computed using partial least squares regression techniques. The NIRS calibration equation $\mathrm{R}^{2}$ values were $0.93,0.93$, and 0.89 for $24-, 30$-, and $48-\mathrm{h}$ ivNDFD. Results suggest that the modified ivNDFD method using rumen fluid primed with a mixture of carbohydrate and urea (CG method) reduced interassay error.

Key words: neutral detergent fiber digestibility, in vitro, forage

\section{INTRODUCTION}

To be certified by the National Forage Testing Association (NFTA, 2008), commercial forage testing laboratories must meet standards for inter- and intraassay errors for DM, CP, and NDF assays. However, no such standard exists for in vitro NDF digestibility (ivNDFD; NFTA, 2008). Fiber digestibility is an important indicator of forage quality. Forage fiber digestibility can range from approximately 20 to nearly $80 \%$ of the total fiber (Oba and Allen, 1999) and can account for as much as $75 \%$ of the digestible energy of forage DM (NRC, 2001). Methods for measuring fiber digestibility are not standardized, and tend to be imprecise relative to assays for DM, CP, and NDF (Mentink et al., 2006). Research and commercial forage testing laboratories most commonly use in vitro procedures that are modifications of the procedure of Goering and Van Soest (1970). Estimates of NDF digestibility vary from laboratory to laboratory because of differences in the laboratory assay, which makes it difficult to compare results between laboratories or to incorporate fiber digestibility into ration-balancing software. In addition, in vitro estimates of fiber digestibility tend to vary from 
run to run within a laboratory because of the variable activity of rumen fluid. Others have recognized significant interassay error with in vitro techniques (Schofield and Pell, 1995; Hall et al., 1998; Rymer et al., 2005).

Goeser and Combs (2009) recently developed an alternative technique to measure in vitro NDF digestibility. Interassay variation was significantly reduced when ground cellulose was added to rumen fluid inoculum and the mixture was allowed to reach a standard gas pressure before sample inoculation. The priming technique resulted in reduced interassay error, or improved precision, relative to a modified Goering and Van Soest (1970) ivNDFD assay. However, estimates of 24-h ivNDFD were lower for the priming technique than estimates based on the modified Goering and Van Soest assay.

In commercial laboratories, most forage analyses are done by near-infrared reflectance spectroscopy (NIRS). The precision of NIRS calibration equations depends on the precision of the analytical technique used to calibrate the NIRS instrument (Shenk and Westerhaus, 1994) and previous attempts to calibrate NIRS to ivNDFD for diverse feeds have been unsuccessful because of imprecision in the laboratory technique (Andres et al., 2005; Mentink et al., 2006). An ivNDFD analytical assay with lower interassay error may allow for NIRS calibrations with improved calibration statistics.

The purpose of this study was not to determine which method may be more accurate, but to compare the precision of the methods. We compared precision by measuring intra- and interassay error for the 3 ivNDFD methods. The modified priming technique was then used to calibrate NIRS by using $24-, 30-$, and 48 -h ivNDFD data for validation of the modified priming technique precision.

\section{MATERIALS AND METHODS}

Two experiments were completed. Experiment A compared 3 in vitro NDF digestion techniques. Experiment B evaluated NIRS calibration statistics when 24-, 30-, and 48-h ivNDFD were predicted by using the modified priming technique as a reference procedure.

\section{Experiment A-Comparing ivNDFD Estimates, and Intra- and Interassay Precision of 3 ivNDFD Methods}

Each of the 3 ivNDFD techniques evaluated in this experiment used rumen fluid inoculum collected and pooled from 2 ruminally cannulated, lactating dairy cows. The first method evaluated was a modified Goering and Van Soest (1970) ivNDFD technique (GV) described by Goeser and Combs (2009). The second method was a modification of the priming technique described by Goeser and Combs (2009; CG), and the third method used unprimed inoculum that had been held until it reached the same gas pressure as in the CG method (UN).

Two forages, alfalfa silage and wheat straw, were analyzed with each of the 3 ivNDFD methods. Both forages were analyzed by Dairyland Laboratories Inc. (Arcadia, WI) by AOAC (2006) methods for DM (method 930.15), CP (method 954.01), and ash (method 942.15). The methods described by Goering and Van Soest (1970) were used to sequentially determine $\mathrm{ADF}$ and sulfuric acid-lignin. Both forages were dried at $60^{\circ} \mathrm{C}$ for $48 \mathrm{~h}$ in a forced-air oven and ground to pass a 1-mm Wiley mill screen (Arthur H. Thomas, Philadelphia, PA) before submission for chemical analysis or for in vitro fiber digestibility. The in vitro NDF digestion assays were conducted as follows.

Approximately $0.5 \mathrm{~g}$ of dried, ground forage sample was weighed into tared, labeled filter bags with a mean pore size of $35 \mu \mathrm{m}$ (F57, Ankom Technology, Macedon, NY). The CG and UN samples were prepared and digested in a manner similar to the rumen fluid priming method, and the GV samples were prepared and digested in a manner similar to the GV technique described by Goeser and Combs (2009). The forage fiber bags remained sealed for the entire procedure for each of the 3 methods. Five repetitions were completed and each repetition included zero hour, 5 digestion time points $(24,28,48,54$, and $72 \mathrm{~h})$, and blank samples analyzed in triplicate for each of the 3 techniques described.

Although the forage samples were prepared in a similar manner, the CG and UN methods used different rumen fluid inoculum preparation procedures based on the methods of Goeser and Combs (2009).

Rumen Fluid Collection and GV Flask Inoculation. The Research Animal and Resource Center of the College of Agriculture and Life Sciences, University of Wisconsin-Madison, approved the animal experimental protocol. At approximately $0630 \mathrm{~h}$ on the day of inoculation, all flasks were subjected to continuous $\mathrm{CO}_{2}$ flow, and $2 \mathrm{~mL}$ of reducing solution was added to each flask designated to the GV. At $0645 \mathrm{~h}$, approximately $1 \mathrm{~L}$ of rumen fluid was collected from each of 2 cannulated, lactating cows into prewarmed, glass-lined Thermoses. The donor cows were fed a $97 \%$ forage and $3 \%$ concentrate diet ad libitum, once daily at $0700 \mathrm{~h}$. The rumen fluid inoculum was strained through 4 layers of cheesecloth while under $\mathrm{CO}_{2}$ flow, and fluid from each cow was pooled in a 2,000-mL Erlenmeyer flask. Approximately $800 \mathrm{~mL}$ of strained, pooled rumen fluid was used to inoculate the GV flasks immediately, with $10 \mathrm{~mL}$ of rumen fluid inoculum per flask. The period from rumen fluid collection to GV flask inoculation was approximately $15 \mathrm{~min}$. 
CG Primer. The CG primer consisted of (\% of DM) $40 \%$ cellulose (Whatman no. 42 ashless filter paper, Whatman International Ltd., Maidstone, UK; ground to pass a $1-\mathrm{mm}$ screen), $20 \%$ urea, $20 \%$ corn starch, and $20 \%$ cellobiose. This primer differed from the cellulose primer used by Goeser and Combs (2009).

CG Rumen Fluid Priming Procedure and $C G$ and $\boldsymbol{U N}$ Flask Inoculation. At $0630 \mathrm{~h}$ on the day of inoculation, $0.3125 \mathrm{~g}$ of primer was combined with 250 $\mathrm{mL}$ of buffer solution and $40 \mathrm{~mL}$ of reducing solution in each of two 1,000-mL side-arm Erlenmeyer flasks designated for the CG method. The buffer and reducing solutions were prepared as described by Goering and Van Soest (1970). Two separate 1,000-mL side-arm Erlenmeyer flasks containing only $250 \mathrm{~mL}$ of buffer and $40 \mathrm{~mL}$ of reducing solution were used for the UN method. The primer was not used with the UN method. All 1,000-mL flasks were gassed with $\mathrm{CO}_{2}$ for $15 \mathrm{~min}$ while rumen fluid inoculum was collected. At $0645 \mathrm{~h}$, $250 \mathrm{~mL}$ of strained, pooled rumen fluid was added to each of the CG and UN 1,000-mL flasks. The CG and UN flasks were then sealed with rubber stoppers, set in an incubating $\left(39^{\circ} \mathrm{C}\right)$ shaker, and allowed to reach 37.4 $\mathrm{mmHg}$ of pressure, which corresponded to $30 \mathrm{~mL}$ of gas production or $0.12 \mathrm{~mL}$ of gas production/ $\mathrm{mL}$ of rumen fluid inoculum. The amount of gas production to reach $37.4 \mathrm{mmHg}$ was determined through manual calibration by forcing known amounts of gas into a sealed 1,000-mL side-arm flask and measuring corresponding pressures with an electronic pressure sensor. After CG or UN flasks averaged $37.4 \mathrm{mmHg}$ per flask, the contents of the 1,000-mL Erlenmeyer flasks were recombined under $\mathrm{CO}_{2}$ and used to inoculate the UN or CG samples with $22 \mathrm{~mL}$ of inoculum solution per flask.

Sample Analysis. At approximately $1500 \mathrm{~h}$ each day, all remaining forage fiber bags were deflated with a plastic rod while purging the in vitro flask with $\mathrm{CO}_{2}$. Samples were removed at 24, 28, 48, 54, and $72 \mathrm{~h}$ after inoculation. Fermentations were terminated by rinsing the bags with ambient-temperature distilled water until the effluent was clear, similar to the technique described by Eun et al. (2007). Sample NDF content was determined by using a neutral detergent solution containing $\alpha$-amylase and sodium sulfite, according to the procedure described by Goering and Van Soest (1970) adapted for an Ankom ${ }^{200}$ Fiber Analyzer (Ankom Technology). Neutral detergent fiber percentages were determined using the following equation:

$$
\begin{gathered}
\mathrm{NDF}(\% \text { of } \mathrm{DM})=[(\text { bag } w t+\text { residue }) \\
-(\text { bag wt } \times \text { bag correction factor })] / \\
{[(\text { bag } w t+\text { sample })-(\text { bag } w t)] \times 100 .}
\end{gathered}
$$

The bag correction factor is the weight of an empty, sealed bag divided by the weight of the same bag after undergoing the ruminal in vitro and NDF procedure. Neutral detergent fiber digestibility was determined by using the following equation:

$$
\begin{gathered}
\operatorname{NDFD}(\% \text { of } \mathrm{NDF})= \\
100 \times\left[\left(\mathrm{NDF}_{0 \mathrm{~h}}-\mathrm{NDF}_{\text {residue }}\right) /\left(\mathrm{NDF}_{0 \mathrm{~h}}\right)\right]
\end{gathered}
$$

Statistical Analysis. The complete data set was analyzed as a randomized complete block design with subsampling by using PROC MIXED (SAS Institute Inc., Cary, NC). The model used was as follows:

$$
\begin{gathered}
Y_{\mathrm{ijkl}}=\mu+\mathrm{R}_{\mathrm{i}}+\mathrm{M}_{\mathrm{j}}+\mathrm{T}_{\mathrm{k}}+\mathrm{F}_{\mathrm{l}}+\mathrm{RM}_{\mathrm{ij}}+\mathrm{RF}_{\mathrm{il}} \\
+\mathrm{RT}_{\mathrm{ik}}+\mathrm{MT}_{\mathrm{jk}}+\mathrm{TF}_{\mathrm{kl}}+\mathrm{RMF}_{\mathrm{ijl}}+\mathrm{RTF}_{\mathrm{ikl}}+\mathrm{e}_{\mathrm{ijk} \mathrm{l}},
\end{gathered}
$$

where $Y_{\mathrm{ijkl}}$ is the NDFD (dependent variable), $\mu$ is the population mean, $R_{i}$ is the random effect of repetition $i, M_{j}$ is the fixed effect of method, $T_{k}$ is the fixed effect of time, $F_{1}$ is the fixed effect of feed, $R M_{i j}$ is the interaction between repetition and method, $\mathrm{RF}_{\mathrm{il}}$ is the interaction between repetition and feed, $\mathrm{RT}_{\mathrm{ik}}$ is the interaction between repetition and time, $\mathrm{MT}_{\mathrm{jk}}$ is the interaction between method and time, $\mathrm{TF}_{\mathrm{kl}}$ is the interaction between time and feed, $\mathrm{RMF}_{\mathrm{ij} \mathrm{l}}$ is the interaction between repetition, method, and feed, $\mathrm{RTF}_{\mathrm{ikl}}$ is the interaction between repetition, time, and feed, and $\mathrm{e}_{\mathrm{ijkl}}$ is the random residual error, which is assumed to be normally distributed. The data sets were also separated by method and analyzed using PROC GLM (SAS Institute Inc.) to obtain repetition sums of squares. The model used was as follows:

$$
\mathrm{Y}_{\mathrm{ijkl}}=\mu+\mathrm{R}_{\mathrm{i}}+\mathrm{T}_{\mathrm{j}}+\mathrm{F}_{\mathrm{k}}+\mathrm{e}_{\mathrm{ijkl}},
$$

where $Y_{\mathrm{ijk}}$ is the NDFD (dependent variable), $\mu$ is the population mean, $R_{i}$ is the fixed effect of repetition $i, T_{j}$ is the fixed effect of time, $F_{k}$ is the fixed effect of feed, and $e_{i j k l}$ is the random residual error, which is assumed to be normally distributed. Repetition variance, or interassay error, was estimated with repetition sums of squares. Repetition sums of squares for each technique were compared by using an $F$-test. Significance was declared at $P<0.05$. Variance within runs was evaluated by using Levene's test (Levene, 1960), in which ANOVA was performed on the absolute deviation of each observation from the median of its group. A group was specified as the triplicate observations for each method, feed, and time point combination. Significance was declared at $P<0.05$. 


\section{Experiment B}

The objective of this experiment was to determine the feasibility of NIRS for predicting CG ivNDFD. Fifty-four forages collected from the University of Wisconsin Marshfield Soils and Forage Analysis Laboratory (Marshfield, WI) were dried at $60^{\circ} \mathrm{C}$ for $48 \mathrm{~h}$ in a forced-air oven and ground to pass a 1-mm Wiley mill screen (Arthur H. Thomas, Philadelphia, PA). The forage set included 27 alfalfa (Medicago sativa L.) hays and silages, 12 whole-plant corn (Zea mays L.) silages, 9 timothy (Phleum pretense L.) hays and silages, and 5 oat (Avena sativa L.) hays and 1 wheat (Triticum aestivum) straw. The forages were selected to represent a wide range in maturity and fiber concentration. The set of 54 forages was digested for 24, 30, and $48 \mathrm{~h}$ in duplicate within a repetition by using the CG method described above. The 54 forages were not analyzed with the UN or GV methods because of time and resource constraints. Each forage sample was digested in 3 separate repetitions and for 24,30 , and $48 \mathrm{~h}$ with duplicate subsamples for each repetition and time point combination. Eighteen forages were analyzed in each repetition, with an alfalfa silage internal standard included in each repetition.

Following ivNDFD analysis of all forages, undigested and ground forage samples were packed into a cylindrical sample holder equipped with a quartz window and scanned between 400 and 2,498 $\mathrm{nm}$ according to the procedures of Marten et al. (1983) on a near-infrared reflectance spectrophotometer (model 6500; Foss-NIR System, FFoss, Silver Spring, MD) fit with a spinning cup holder. Forage sample data included 24-, 30-, and 48-h ivNDFD for development of calibration equations. Calibrations were computed using partial least squares regression techniques with a 2, 4, 4, 1 math treatment and the procedures of Mentink et al. (2006). Calibration performance was evaluated by using cross-validation (Shenk and Westerhaus, 1991), where prediction error was evaluated by dividing the calibration samples into subsets $(\mathrm{n}=4)$, with 1 subset reserved for validation and the remaining subsets used for calibration. Crossvalidation was completed until all subsets were used for validation once. The strength of calibration performance was based on the coefficient of determination $\left(\mathrm{R}^{2}\right)$, the standard error of calibration, the standard error of cross-validation, and 1 minus the variance ratio $(1-\mathrm{VR})$.

\section{RESULTS AND DISCUSSION}

\section{Terminology}

Neutral detergent fiber digestibility (NDFD, \% of $\mathrm{NDF}$ ) and digestible NDF (dNDF, \% of DM) are 2 terms used to report in vitro digestion parameters of NDF. However, these terms represent different calculations and associated errors. These terms should not be used interchangeably. The NDFD is calculated as a percentage of total NDF, and the value increases with time. The NDF assay error is included within NDFD calculation twice, once through determination of NDF content at time 0 and again in determination of the NDF residue after digestion at time $T$. The dNDF is calculated as a percentage of DM, and the value of dNDF declines with time. The dNDF term is inherently more precise because the NDF assay error is included in calculation only once. We use the term NDFD to be consistent with the value most commonly reported by commercial laboratories (NFTA, 2008).

In experiment $\mathrm{A}$, the primer used by Goeser and Combs (2009) was changed from pure cellulose to a mixture of carbohydrates and urea that would be similar in chemical composition to a diet that was $60 \%$ forage and $40 \%$ concentrate, theoretically providing substrate for proteolytic, cellulolytic, and noncellulolytic microbial populations. The effect of the primer was also separated from the effect of allowing rumen fluid to produce 0.12 $\mathrm{mL}$ of gas $/ \mathrm{mL}$ of rumen fluid inoculum by comparing CG with UN.

Forage samples analyzed in vitro differed by approximately $30 \%$ units in NDF content, 44.9 and $73.6 \%$ for alfalfa silage and wheat straw, respectively. Crude protein $(20.62,6.36)$, ADF $(41.44,57.03)$, lignin (8.37, $9.71)$, fat $(3.75,0.82)$, and ash content $(10.22,7.11)$ as a percentage of DM also differed numerically for the alfalfa and straw samples, respectively. Testing the precision of ivNDFD estimates using 2 forage samples ranging in NDF content in a highly replicated design may have been a more robust set of conditions to test precision of the in vitro NDF digestion techniques than those of Goeser and Combs (2009) in a prior study.

The amount of time for the combination of 1,000$\mathrm{mL}$ side-arm Erlenmeyer flasks (CG or UN) to reach an average of $37.4 \mathrm{mmHg}$ varied from 1 to $3 \mathrm{~h}$. Mean ivNDFD estimates across both feeds and all time points differed at 35.51 and $35.94 \%$ of NDF for the CG and GV, respectively (Table 1); however, this difference was most likely not biologically relevant. This difference was most likely caused by the CG 24-h ivNDFD mean being lower $(P<0.05)$ than the GV method. The 24 -h observation was similar to what Goeser and Combs (2009) observed. However, the difference in 24-h ivNDFD between $\mathrm{CG}$ and $\mathrm{GV}(1.3 \%$ units, $P<0.05)$ was numerically smaller than the difference at $24 \mathrm{~h}$ previously reported by Goeser and Combs (2009). Estimated ivNDFD for CG and GV were similar at 28, 48, and 54 $\mathrm{h}$, and CG was greater after $72 \mathrm{~h}$ of digestion (Table 1 ). In the previous experiment (Goeser and Combs, 2009), 
Table 1. In vitro NDF digestion (ivNDFD) estimates for 3 techniques in experiment $\mathrm{A}$

\begin{tabular}{llllll}
\hline & \multicolumn{4}{c}{ ivNDFD technique $^{1}$} & \\
\cline { 2 - 4 } ivNDFD, \% of NDF & GV & UN & CG & SEM & $P<$ \\
\hline Mean $^{2}$ & $35.9^{\mathrm{a}}$ & $34.9^{\mathrm{c}}$ & $35.5^{\mathrm{b}}$ & 0.1 & 0.01 \\
Time, h & & & & & \\
24 & $24.9^{\mathrm{a}}$ & $22.1^{\mathrm{c}}$ & $23.6^{\mathrm{b}}$ & 0.4 & 0.01 \\
28 & $28.1^{\mathrm{a}}$ & $26.4^{\mathrm{b}}$ & $28.1^{\mathrm{a}}$ & 0.4 & 0.01 \\
48 & 40.6 & 39.9 & 39.8 & 0.3 & 0.17 \\
54 & $42.0^{\mathrm{a}}$ & $41.4^{\mathrm{b}}$ & $41.5^{\mathrm{ab}}$ & 0.2 & 0.08 \\
72 & $44.0^{\mathrm{b}}$ & $44.8^{\mathrm{a}}$ & $44.5^{\mathrm{a}}$ & 0.2 & 0.01 \\
\hline
\end{tabular}

${ }^{\mathrm{a}-\mathrm{c}}$ Means in rows with differing superscripts differ $(P<0.05)$.

${ }^{1}$ ivNDFD technique: GV = modified method of Goering and Van Soest (1970); UN = rumen fluid inoculum held to a standard pressure without primer; $\mathrm{CG}=$ Combs-Goeser ivNDFD method.

${ }^{2}$ Mean $=$ ivNDFD ( $\%$ of NDF) estimate across 5 digestion time points.

the depression in 24-h ivNDFD values with the primed inoculum relative to the traditional method could have been due to a greater substrate-to-inoculum ratio in the primed technique in vitro flasks during digestion. In the present experiment, 24-h ivNDFD estimates were still slightly depressed, but ivNDFD estimated at later time points with the CG and GV were similar.

Two tests of the precision of analytical techniques are presented here: the $F$-test of repetition sums of squares, which compares interassay variance (Table 2), and Levene's test for inequality of variance, which assesses intraassay error (Table 3). Both inter- and intraassay variance should be evaluated when assessing laboratory assays. Recently, error estimates of ivNDFD methods mean comparisons were presented (Hall and Mertens, 2008). The standard errors were calculated from 2 repetitions, but the statistical analysis accounted for repetition variance, or interassay error. The significance of this repetition effect was not discussed. The standard error estimates in this study are representative of only

Table 2. In vitro NDF digestion (ivNDFD) estimate repetition sums of squares for 3 techniques ${ }^{1}$ in experiment A

\begin{tabular}{|c|c|c|c|c|}
\hline \multicolumn{3}{|c|}{ Repetition sum of squares $^{2}$} & \multirow[b]{2}{*}{$F$-value ${ }^{3}$} & \multirow[b]{2}{*}{$P<$} \\
\hline GV & UN & $\mathrm{CG}$ & & \\
\hline 228.86 & - & 19.46 & 11.76 & 0.02 \\
\hline 228.86 & 55.01 & - & 4.16 & 0.10 \\
\hline- & 55.01 & 19.46 & 2.83 & 0.17 \\
\hline
\end{tabular}

${ }^{1}$ ivNDFD technique: GV = modified method of Goering and Van Soest (1970); UN = rumen fluid inoculum held to a standard pressure without primer; $\mathrm{CG}=$ Combs-Goeser ivNDFD method.

${ }^{2}$ Repetition type III sum of squares $=$ sum of squares attributed to repetition following ANOVA. This is a measure of interassay variance.

${ }^{3} F$-value $=$ larger sum of squares value/smaller sum of squares value on 4 (4 df).
Table 3. Levene's test ${ }^{1}$ for equality of variance for 3 in vitro NDF digestion (ivNDFD) techniques ${ }^{2}$ in experiment $\mathrm{A}$

\begin{tabular}{|c|c|c|c|c|}
\hline \multicolumn{3}{|c|}{ Levene's test, ${ }^{3} \%$ of NDF } & \multirow[b]{2}{*}{ SEM } & \multirow[b]{2}{*}{$P<$} \\
\hline GV & $\mathrm{UN}$ & $\mathrm{CG}$ & & \\
\hline 3 & 1.4 & 1.3 & 0.1 & 0.68 \\
\hline \multicolumn{5}{|c|}{$\begin{array}{l}{ }^{1} \text { Levene's test (Levene, 1960) is a measure of intraassay error. } \\
{ }^{2} \text { ivNDFD technique: GV = modified method of Goering and Van Soest } \\
(1970) \text {; UN = rumen fluid inoculum held to a standard pressure with- } \\
\text { out primer; CG = Combs-Goeser ivNDFD standardization. } \\
{ }^{3} \text { Repetition mean absolute deviation from median of triplicate sub- } \\
\text { samples ( } \% \text { of NDF) = mean following Levene's test in which ANOVA } \\
\text { was completed on absolute deviations from the median of each group } \\
\text { for } 3 \text { ivNDFD techniques. }\end{array}$} \\
\hline
\end{tabular}

intraassay error. Our results suggest that with ruminal in vitro assays, interassay error differed significantly among in vitro techniques and warrants discussion.

Repetition sums of squares were reduced more than 10-fold with CG compared with GV $(P<0.02$; Table 2 ). These results suggest that adding a priming substrate to the rumen fluid and holding the inoculum until it generated $0.12 \mathrm{~mL}$ of gas $/ \mathrm{mL}$ of rumen fluid was more effective in reducing interassay error than was the GV or UN method. The results of this experiment also indicate that the reduction in intraassay error was observed across all 5 digestion time points. The CG appeared to reduce the variable nature of rumen fluid and yielded ivNDFD estimates less affected by varying inoculum activity.

Results of this study also indicate that pretreatment of rumen fluid did not affect intraassay error (Table 3 ). The mean deviations within groups for each method were not different after Levene's test (Levene, 1960). Adding a primer and allowing bacterial growth did not increase the precision of triplicate ivNDFD estimates in each repetition. The results suggest that priming affects only one of the errors to which ivNDFD estimates are subject. This observation is consistent with prior observations by Goeser and Combs (2009).

In vitro NDFD estimates from the UN technique, in which rumen fluid was not primed but was held in the preinoculation flask until the gas pressure reached $37 \mathrm{mmHg}$, were not as precise as ivNDFD estimates

Table 4. NDF composition and in vitro NDF digestibility ${ }^{1}$ (ivNDFD) estimate summary statistics for 54 forages used in near-infrared spectroscopy calibration in experiment B

\begin{tabular}{lccccr}
\hline Item & $\mathrm{N}$ & Mean & Minimum & Maximum & \multicolumn{1}{c}{ SD } \\
\hline NDF, \% of DM & 54 & 45.5 & 24.9 & 75.9 & 11.4 \\
24-h ivNDFD, \% of NDF & 54 & 23.2 & 0.9 & 40.8 & 9.5 \\
30-h ivNDFD, \% of NDF & 54 & 30.3 & 6.7 & 49.8 & 10.7 \\
48-h ivNDFD, \% of NDF & 54 & 44.9 & 19.4 & 67.6 & 11.1 \\
\hline
\end{tabular}

${ }^{1}$ Obtained using the Combs-Goeser ivNDFD method. 
Table 5. Calibration statistics for near-infrared spectroscopy (NIRS) prediction of NDF and $\mathrm{CG}^{1}$ in vitro NDF digestibility (ivNDFD) for 54 feeds in experiment B

\begin{tabular}{|c|c|c|c|c|c|c|c|c|}
\hline \multirow[b]{2}{*}{ Item } & \multicolumn{8}{|c|}{ Calibration statistic ${ }^{2}$} \\
\hline & $\mathrm{N}$ & Mean & Minimum & Maximum & SEC & $\mathrm{R}^{2}$ & SECV & $1-\mathrm{VR}$ \\
\hline $\mathrm{NDF}, \%$ of $\mathrm{DM}$ & 53 & 45.4 & 10.9 & 79.9 & 1.9 & 0.97 & 2.4 & 0.95 \\
\hline $24 \mathrm{~h}$ ivNDFD, $\%$ of NDF & 53 & 23.1 & 0.0 & 51.8 & 2.5 & 0.93 & 3.7 & 0.85 \\
\hline $30 \mathrm{~h}$ ivNDFD, $\%$ of NDF & 53 & 30.2 & 0.00 & 62.79 & 2.82 & 0.93 & 4.4 & 0.83 \\
\hline $48 \mathrm{~h}$ ivNDFD, $\%$ of NDF & 53 & 44.9 & 11.9 & 78.0 & 3.6 & 0.89 & 5.0 & 0.79 \\
\hline
\end{tabular}

attained by the CG method. This observation suggests that both adding a primer and allowing $0.12 \mathrm{~mL}$ of gas production $/ \mathrm{mL}$ of rumen fluid are necessary to achieve the greatest ivNDFD precision over time.

The forage set used in experiment B, with summary statistics provided in Table 4, is comparable in size to that used by De Boever et al. (1996). The authors used a set of similar size to determine the acceptability of NIRS prediction for digestion parameters. This size set may be considered a small-scale, or local, calibration set (Aastveit and Marum, 1993). A local calibration set offers validation of the precision of the reference technique and may determine the potential of the reference technique for developing universal, or large-scale, NIRS calibrations. The NIRS calibration equation $\mathrm{R}^{2}$ values were $0.93,0.93$, and 0.89 for $24-, 30-$, and $48-\mathrm{h}$ ivNDFD, respectively (Table 5). The NIRS calibration equation $\mathrm{R}^{2}$ value for 48 -h ivNDFD in this study was higher than in previously published values for ivNDFD (Andres et al., 2005; Mentink et al., 2006). Further, to our knowledge, this is the first study to show similar NIRS calibration statistics for 24-, 30-, and 48-h ivNDFD measurements with a diverse set of forages. No comparisons of ivNDFD NIRS calibration $\mathrm{R}^{2}$ values with previous research could be made for the 24- and 30-h time points; however, the NIRS calibration equation statistics for 24 and $30 \mathrm{~h}$ were similar to those at $48 \mathrm{~h}$, and the 48-h statistics suggest improved reference technique precision.

High-quality NIRS calibration equations depend on the precision of the analytical reference procedure used to calibrate the instrument (Mentink et al., 2006). Only precise reference techniques result in successful NIRS calibrations; hence, our observed successful NIRS calibration using the CG as a reference technique for 24-, 30-, and 48-h ivNDFD suggests the CG offers improved precision relative to the in vitro techniques used by Andres et al. (2005) and Mentink et al. (2006). These statistics support the notion that the CG ivNDFD technique offers improved precision relative to modified
GV techniques. However, a larger sample set is necessary for large-scale NIRS calibration.

\section{CONCLUSIONS}

Priming rumen fluid inoculum with $1.25 \mathrm{mg}$ of a mixture of carbohydrates and nitrogen $/ \mathrm{mL}$ of rumen fluid inoculum, and allowing the solution to produce $37.5 \mathrm{mmHg}$ of pressure before inoculation reduced interassay error while producing ivNDFD estimates equivalent to those of a modified Goering and Van Soest (1970) method. Results suggest that by using the CG method, ivNDFD estimates are less likely to be affected by varying rumen fluid inoculum activity. The preliminary NIRS calibration equations with $\mathrm{R}^{2}>0.89$ using the CG as a reference procedure for 24-, 30-, and 48-h ivNDFD substantiate the improvement in precision observed for the CG.

\section{REFERENCES}

Aastveit, A. H., and P. Marum. 1993. Near-infrared reflectance spectroscopy: different strategies for local calibrations in analyses of forage quality. Appl. Spectrosc. 47:463-469.

Andres, S., F. J. Giraldez, J. S. Gonzalez, R. Pelaez, N. Prieto, and A. Calleja. 2005. Prediction of aspects of neutral detergent fibre digestion of forages by chemical composition and near-infrared reflectance spectroscopy. Aust. J. Agric. Res. 56:187-193.

AOAC. 2006. Official Methods of Analysis. 18th ed. Association of Official Analytical Chemists International, Washington, DC.

De Boever, J. L., B. G. Cottyn, D. L. Brabander, J. M. Vanacker, and Ch. V. Bocque. 1996. Prediction of the feeding value of grass silages by chemical parameters, in vitro digestibility and near-infrared reflectance spectroscopy. Anim. Feed Sci. Technol. 60:103-115.

Eun, J. S., K. A. Beauchemin, and H. Schulze. 2007. Use of exogenous fibrolytic enzymes to enhance in vitro fermentation of alfalfa hay and corn silage. J. Dairy Sci. 90:1440-1451.

Goering, H. K., and P. J. Van Soest. 1970. Forage Fiber Analyses (Apparatus, Reagents, Procedures, and Some Applications). Agric. Handbook No. 379. ARS-USDA, Washington, DC

Goeser, J. P., and D. K. Combs. 2009. An alternative method to assess 24-h ruminal in vitro neutral detergent fiber digestibility. J. Dairy Sci. 92:3833-3841.

Hall, M. B., and D. R. Mertens. 2008. In vitro fermentation vessel type and method alter fiber digestibility estimates. J. Dairy Sci. 91:301-307. 
Hall, M. B., A. N. Pell, and L. E. Chase. 1998. Characteristics of neutral detergent-soluble fiber fermentation by mixed ruminal microbes. Anim. Feed Sci. Technol. 70:23-39.

Levene, H. 1960. Contributions to Probability and Statistics: Essays in Honor of Harold Hotelling. Stanford University Press, Stanford, CA.

Marten, G. C., J. L. Halgerson, and J. H. Cherney. 1983. Quality prediction of small grain forages by near-infrared reflectance spectroscopy. Crop Sci. 23:94-96.

Mentink, R. L., P. C. Hoffman, and L. M. Bauman. 2006. Utility of near-infrared reflectance spectroscopy to predict nutrient composition and in vitro digestibility of total mixed rations. J. Dairy Sci. 89:2320-2326.

National Forage Testing Association. 2008. 2008 Certification Program Requirements. http://www.foragetesting.org/files/2008/ Requirements.pdf Accessed August 1, 2008.

NRC. 2001. Nutrient Requirements of Dairy Cattle. 7th rev. ed. Natl. Acad. Sci., Washington, DC.

Oba, M., and M. S. Allen. 1999. Evaluation of the importance of the digestibility of neutral detergent fiber from forage: Effects on dry matter intake and milk yield of dairy cows. J. Dairy Sci. 82:589-596.

Rymer, C., B. A. Williams, A. E. Brooks, D. R. Davies, and D. I. Givens. 2005. Interlaboratory variation of in vitro cumulative gas production profiles of feeds using manual and automated methods. Anim. Feed Sci. Technol. 123:225-241.

Schofield, P., and A. N. Pell. 1995. Validity of using accumulated gas pressure readings to measure forage digestion in vitro- $\mathrm{A}$ comparison involving 3 forages. J. Dairy Sci. 78:2230-2238.

Shenk, J. S., and M. O. Westerhaus. 1991. Population definition, sample selection, and calibration procedures for near infrared reflectance spectroscopy. Crop Sci. 31:469-474.

Shenk, J. S., and M. O. Westerhaus. 1994. The application of near infrared reflectance spectroscopy (NIRS) to forage analysis. Pages 406-449 in Forage Quality, Evaluation, and Utilization. G. C. Fahey, M. Collins, D. R. Mertens, and L. E. Moser, ed. Am. Soc. Agron., Madison, WI. 